XXV. On the Effects of certain Agents on Insects, in a Letter addressed to William Spence, Esq., F.R.S., \&c., by JоHN Davy, Esq., M.D., F.R.S.

[Read 5th May, 1851.]

My dear Sir,

Is a letter which I had the honour to address to you last year relative to the effects of change of temperature on insect life, in a very limited way, I expressed the hope of being able to continue the experiments and extend them to other agencies on the same class of beings. This I have in some measure accomplished, and I propose now to make known to you the results, which be pleased to use in any way you may think proper.

The inquiry was entered on in the last week of November, and owing to the extraordinary mildness of the winter months has been continued almost uninterruptedly to the present time, viz. the middle of March. During the whole of this period the thermometer here has never for twenty-four hours been below the freezing point ; it has oftener, by day, been above $40^{\circ}$ of Farenheit than below that degree. This mildness of atmosphere has been accompanied with unusual humidity, and an extraordinary fall of rain: in November the amount of rain here was 13.26 inches, in December 5.46 inches, in January 19.54 inches, as measured by the pluviometer; and scarcely a day has passed during the whole of the period that insects of several kinds have not been seen on the wing or abroad in the open air.

For the sake of order, and to be better able to compare the results, I shall first notice those experiments which I have made on the effects of temperature on insects; next, of gases; and lastly, of vapours. Should my account of the trials be found tedious, I trust it will be borne with, as without some minuteness of detail, accuracy on such a subject is hardly attainable. For the names of the species, when they are assigned, you know that I am indebted to an able Entomologist, Francis Walker, Esq., who at your request was so obliging as to examine most of the individuals, the subjects of the experiments, and to return them labelled.

1. On the Effect of Changes of Temperature on certain Insects.

I shall first notice the effect of reduced temperature, that is, of a reduction of many degrees below the annual mean, and also below the freezing point. 
On the 28th of November exposed a bee (Bombus hortorum), in a languid state as to activity, in a room, the temperature of which was $54^{\circ}$, to the open air of the temperature $32^{\circ}$; it immediately became more active, endeavouring to get from under the glass which confined it, even spreading its wings and attempting flight. How long it remained thus active I did not stop to watch. Left over night, it was found the following morning quite torpid as if dead. A register thermometer, placed beside it on the grass, indicated $25^{\circ}$ as the minimum. After having been brought into a room, of the temperature $52^{\circ}$, in about half an hour it revived, and, when touched, feebly moved its legs and walked. The same bee, on the morning of the $30 \mathrm{th}$, at a temperature of $48^{\circ}$, moved its limbs slowly when touched. Exposed to the open air at $22^{\circ}$, rising in the course of the day to $28^{\circ}$, it soon became completely torpid, moving no part when touched. It revived as before, at a temperature of $56^{\circ}$.

A fly (Musca vomitoria), on the 8 th December, was active, flying about within doors, at a temperature of $52^{\circ}$; it became dull and averse from motion at $40^{\circ}$, and more so at $33^{\circ}$, at which temperature it did not move till touched, and then sluggishly; even at $28^{\circ}$ it was not torpid, and that after exposure during the night to a temperature of $23^{\circ}$, as indicated by a register thermometer. On the following day it was exposed under the same circumstances, in company with a bee (a Bombus), to the open air at $28^{\circ}$; the bee presently became torpid, the fly not,--moving its legs languidly when touched. The bee, in this its torpid state, bore a temperature of $22^{\circ}$ : it remained motionless at $30^{\circ}$ : for two hours it did not revive at $54^{\circ}$ : when placed on the warm hand and breathed upon, it presently began to move one of its legs, and shortly after another, and in less than a minute it was walking on the hand; removed from the hand, in a few seconds it became motionless, showing no signs of life even when touched, and this at $54^{\circ}$; replaced on the hand, it again became active, but not so soon as before, its hind legs first moved; the movement was that of passing the one over the other, as in the act of cleaning them; next the fore legs were moved in the same manner, the wings remaining motionless. Removed from the hand, a state of torpor was induced in a few seconds.

A fly (Musca stabulans), found within doors on the 13th December, exposed to the open air at $41^{\circ}$, became motionless, except when touched, when it was tolerably active: even at $54^{\circ}$ it appeared to be in the same state, not torpid, moving only when touched, and excited to motion by the gentlest touch. At $31^{\circ}$ it 
became quite torpid, so that when roughly moved it showed no signs of life. It was exposed to a temperature of $22^{\circ}$, without fatal effect.

A small fly (Piophila casei), pretty active in a window at $44^{\circ}$ on the 19 th December, did not become torpid at $38^{\circ}$, moving its legs when touched, nor at $33^{\circ}$ : but at $31^{\circ}$ torpor was produced, and it bore without fatal effect a reduction of temperature to $22^{\circ}$. After this it was active at $36^{\circ}$, and flew away when let into the open air in the shade.

On the 23rd February exposed a fly (Anthomyia mitis) to a night temperature of $25^{\circ}$ (the lowest); the following morning at 9 A.м. it was languid at $26^{\circ}$, moving its legs sluggishly when touched. On the following night it was again exposed to a temperature of $22^{\circ}$. When taken out of the tube, which was covered with hoar frost, it was motionless for several seconds; but in a minute or two it moved its legs when touched, and, brought into a warm room, it soon became active.

A honey bee (Apis mellifica), active in the open air in sunshine on the 9 th March, became motionless at $40^{\circ}$ in the shade. In a room at $55^{\circ}$ it moved its legs and wings languidly; some hours later at night, at $51^{\circ}$, it was found torpid; breathed on, a languid movement of its wings was reproduced; placed where the temperature was $65^{\circ}$ it presently became active. The following morning at $50^{\circ}$ it was found motionless; breathed on, on the warm hand, a feeble revival was indicated by a slight motion of one of its antennæ, and occasionally of one of its legs: in this state, as it were between life and death, it continued during five days, at a temperature between $50^{\circ}$ and $60^{\circ}$, at the end of which it ceased to give any sign of vitality, the same means being employed to excite it.

These are all the trials I have made on the influence of reduction of temperature: they are smaller in number than I could have wished, owing to the want of opportunities from the extreme mildness of the season, as already adverted to; and even in the few instances in which the reduction of temperature was below the freezing point it may be worthy of remark, that it was owing not so much to the coldness of the atmosphere as to that of the surface, the effect of radiation from the grass plat on which the insects were placed during clear and calm nights, of which for the time of the year there were unusually few.

On the effect of elevation of temperature, to which I shall now proceed, I have also a few results to describe.

On the 19th January exposed a fly (Anthomyia mitis) in a tube 
of thin glass to a temperature of $120^{\circ}$; in two or three minutes it became motionless and was found to be dead. The same effect, in as short a time, was produced on another fly of the same kind by a temperature of $113^{\circ}$. On the 28th January exposed another also of the same kind to a temperature gradually rising (the tube being immersed in water) to $96^{\circ}$. After about an hour the fly that was at first active was found lying at the bottom of the tube, seemingly incapable of standing; in another minute it ceased to move, and did not revive on exposure to the air of the room. Another of the same kind bore well a temperature between $80^{\circ}$ and $90^{\circ}$ for two hours; after exposure to a temperature between $90^{\circ}$ and $100^{\circ}$ less than an hour, it was found dead.

A fly (Musca lanio) on the 30th January was exposed to a temperature between $80^{\circ}$ and $90^{\circ}$, and $90^{\circ}$ and $100^{\circ}$, for several hours ; so long as the air in the tube was below $100^{\circ}$ the fly did not appear to suffer; above $100^{\circ}$, it showed a tendency to become torpid; at $105^{\circ}$, after a very few minutes, it became motionless, and did not revive on exposure to the air of the room.

On the 16th March, a honey bee,--just taken from the open air at $45^{\circ}$, when in sunshine actively on the wing, - was exposed to a gradually increasing temperature. Its activity was not apparently diminished at $80^{\circ}$; at $90^{\circ}$ the sound of its wings had ceased: it was at rest at the bottom of the tube, but in nowise torpid; after a few minutes, at $96^{\circ}$, it became motionless; then taken out, and exposed to the air of the room at $55^{\circ}$, it did not revive; no part of it afterwards moved.

What is known of the habitats of insects in relation to climate, I need hardly remark, amply proves the vast range of temperature at which different species can exist, - each probably restricted to a certain range,- and consequently that a very large number of trials on different species would be required to arrive at any satisfactory conclusion on the influence of temperature on insects generally. One remark I beg to make, in which I think I am warranted by my limited experience,- as to the effect of change of temperature, - viz. that on insects it is different from what it is on the hybernating mammalia; not, as in them, producing a quick transition from active to torpid life, but more commonly a graduated one from great activity to diminished, till motion is altogether lost; and this gradation, whether in becoming torpid from cold, or in recovering from a state of torpor on elevation of temperature. 


\section{On the Effect of certain Gases.}

Carbonic Acid Gas.-On the 19th December placed a fly (Musca stabulans) in a tube in which this gas was in process of being rapidly generated by the action of dilute nitric acid on fragments of limestone. The fly was supported by a perforated diaphragm, so as to be kept above the fluid, and the tube was corked, but not so tight as to prevent entirely the escape of gas, and immersed in water. In a few seconds the fly became motionless: taken out after two - hours, it seemed dead, it did not move even when placed on the warm hand, and breathed on for a minute or two; soon after, the breathing on it being continued, a slight tremulous motion was perceived in its feet, and in a few minutes more decided animation was restored, and it moved when touched, and walked.

December 21st, put a fly (Heteromyza buccata) into a tube full of carbonic acid gas. It became instantly motionless. Kept in the gas about two minutes, it revived in about five minutes after being taken out, and seemed not less active than before. Replaced in the gas after an interval of twenty-four hours, in a few seconds it became motionless; left in the gas another twenty-four hours, it was found dead when taken out.

On the same day, a small fly (an Anthomyia), confined in a wine glass inverted on a plate of glass, was so active (the temperature of the room $56^{\circ}$ ) as to fly from side to side. Introduced a bit of limestone, and added a little nitric acid; the fly at the time was standing on the side of the glass; in two or three seconds, without making any efforts to escape, it lost its hold, and fell into the effervescing fluid, where it was motionless. Taken out after about two minutes, in two or three minutes more it began to move its legs, and shortly was tolerably active, considering its clogged state from its wet wings and legs.

On the 25th December, put a fly (Musca lanio) in an active state at the temperature of the room into the tube, with carbonic acid gas. It immediately became motionless; taken out after twentyfour hours, it was found to be dead.

On the same day put into the gas a small fly of the gnat kind. In two or three seconds it became motionless; after about three or four hours exposure to the gas, on being taken out, and placed on the warm hand and breathed upon, a slight motion of the legs was perceived, but this only for a minute or two, when all marks of life ceased.

On the 26th December, placed two flies, both of them pretty active, (a Heteromyza buccata and a Musca lanio,) in carbonic acid 
gas. They became motionless in a few seconds; left in about an hour, the former did not revive immediately on being taken out, nor even when placed on the warm hand and breathed upon; yet in half an hour it was nearly as active as before. The other fly, similarly treated when taken out, revived in less than a minute on the warm hand. Again immersed in the gas, and now left there about twenty hours, both were found to be dead when taken out.

On the 29th December, repeated the experiments on two flies similar to the preceding, with a like immediate result, they becoming motionless in two or three seconds. Taken out after two hours, they did not revive immediately, even when placed on the warm hand and breathed upon; in ten minutes they had revived, and were much in the same state as to activity as before immersion: the one alert (the Heteromyza), the other sluggish. Thrown again into the gas, they instantly became motionless, - not the slightest movement, even of the legs, could be perceived; had the air in the tube been common air, they would have been excited by the fall; taken out instantly they presently revived. Returned into the gas on the following day, and taken out after three hours, both were found motionless; the Heteromyza, after six hours, was found active; the other fly then was motionless, not moving even when touched; nine hours later it was revived, and active.

On the 9th March placed two honey bees, rather languid at $55^{\circ}$, in the tube, in which carbonic acid gas was in the act of being disengaged; common air was mixed with the gas. They at first became excited and active, used their wings, as if trying to escape; gradually, and pretty rapidly, their activity diminished; and in less than a minute they both dropped down on the diaphragm motionless. Taken out, after remaining in about a quarter of an hour, they remained motionless about an hour and a quarter; now breathed on, they began to move, and shortly, at a temperature of $65^{\circ}$, to which they were transferred from one of $51^{\circ}$, they became active.

Hydrogen Gas.-On the 30th December immersed the same flies, which had revived after exposure to carbonic acid gas on the preceding day, to hydrogen whilst in the act of being generated by means of zinc and dilute muriatic acid. They did not become instantly motionless, but they were so in less than a minute. Taken out after being two hours in the gas, the Heteromyza revived in about a quarter of an hour; the other remained motionless about three hours, then, when touched, it moved freely.

On the 10th March made a similar experiment on a honey bee. As the hydrogen, from the expulsion of common air from the tube, 
became concentrated, the bee became restless; in two or three minutes it fell down, and after a tremulous movement of its limbs for a few seconds, it became motionless. Taken out after being in five minutes, it exhibited, in a few seconds, marks of reviving, its limbs moving in the same tremulous manner as that observed previously to its becoming torpid. On the following day it was alive and tolerably active at $55^{\circ}$, as if nowise injured by the action, on it, of the gas.

Azote.-Put a fly (Heteromyza buccata) into this gas, obtained from common air by the removal of the oxygen by phosphorus, after which removal it was allowed to stand twenty-four hours over water. The fly, in coming in contact with the azote, immediately fell from the side of the tube, and, except a slight motion of one of its legs, it appeared to have been rendered instantly torpid. Taken out after two hours, it revived in about ten minutes, its activity nowise impaired.

Common Air.-Put a fly of the same kind as the preceding into a tube, with common air, confined by a little cotton wool, in a room where all the indoor experiments were made, varying in temperature between $52^{\circ}$ and $60^{\circ}$. From the 5th February, when it was introduced, till the $26 \mathrm{th}$, it seemed little affected; on the 28th it was found dead.

Put a fly (Musca lanio) in a tube, with a small quantity of air, a few times its own volume. This was on the 4th of January; on the 5 th the fly was languid; on the 16 th it was motionless. About two hours after being taken out it showed marks of vitality, and was soon tolerably active. Hardly an appreciable quantity of oxygen, by the test of phosphorus, was found in the residual air ; most of it had been converted into carbonic acid.

On the 19th January put three flies of the same kind as the lastmentioned, pretty active at $45^{\circ}$, into a tube full of water, and inverted it in water; a little air adhered to their wings. Shortly after they were found motionless, the temperature of the room $56^{\circ}$. In about ten minutes after being taken out they revived, and, when dry, they appeared to be as active as before.

Oxygen.-Introduced a fly of the same kind into this gas, over water obtained from the decomposition of chlorate of potash. Though swimming with its feet and part of its body immersed in the water, for twenty-four hours, its activity was nowise impaired:-a few hours later it was found under the water and motionless; on exposure to the air of the room it did not recover. On the 27th January introduced another fly of the same kind into 
oxygen. Twenty-four hours after it was standing dry on the side of the tube, as if in common air, and in like manner on the $31 \mathrm{st}$. On the 1st February it was found swimming on the water; by inclining the tube it got out of the water, attaching itself to the side of the glass; on the following day it was found motionless, and it did not revive on being taken out. There was a slight diminution of the volume of the oxygen, many times the bulk of the fly.

Coal Gas.-Put a fly (Heteromyza buccata) into a tube half-full of water, above which was common air, and introduced a little coal gas as it was generated by the action of heat: no sooner had a few bubbles come in contact with the fly floating on the surface of the water, than from a state of activity it became motionless. Taken out without loss of time, and exposed to the air, it revived in about ten minutes. 'The same fly, exposed to the action of the gas nearly pure, became motionless in two or three seconds. Taken out after about a minute, it gave no signs of life for half an hour ; three hours later, a feeble movement of its legs was perceptible, soon terminating in death.

Sulphuretted Hydrogen.-On the 31st December immersed the same flies, that had been exposed to the action of hydrogen on the preceding day, in sulphuretted hydrogen, as it was slowly disengaged in a tube by the action of dilute muriatic acid on sulphuret of iron. After a few seconds both flies were motionless; and they did not revive when taken out, and that immediately. The effect was the same on another (Heteromyza buccata), and as rapidly.

On the 1st January immersed a fly (Musca hortorum) in a mixture of sulphuretted hydrogen and common air : in a few seconds it became motionless, and though instantly taken out it did not revive. On the same day repeated the experiment on a Hetero$m y z a$, and with like effect: the air in the tube consisted of about two parts common air and one sulphuretted hydrogen. On the same day introduced into the tube in which the gas was in process of being generated, two flies (Trichocera hiemalis, very active, Musca vomitoria, less so). After about an hour both were motionless ; nor did they revive when taken out. So small was the proportion of sulphuretted hydrogen, that, when an attempt was made to ascertain it, it was hardly appreciable.

On the 20th March introduced an active honey bee, just taken, into a mixture of sulphuretted hydrogen and atmospheric air. The very instant it entered it dropt motionless; and not the 
slightest motion of any part was seen afterwards. Taken out, after having been in the tube ten minutes, it did not revive on exposure to the air. The same day repeated the experiment on another honey bee : after a few minutes of restlessness it fell down motionless. Taken out, after about eight minutes, and exposed to the air, in about balf an hour a languid motion of the abdomen was visible, and the same was occasionally seen to occur for about thirty hours, soon after which time it was found motionless and dead. The proportion of sulphuretted hydrogen mixed with the atmospheric air in this instance was very minute. The experiment repeated under the same circumstances with another active honey bee. The result was similar, - the state of torpor, the effect of the very dilute gas, was, on exposure to the air, followed by slight signs of revival, soon terminating in death.

Sulphurous Acid Gas.-On the 24th of January exposed a fly (Heteromyza buccata) to this gas, very much diluted, by kindling a minute portion of sulphur under a wine glass, in which the fly was confined. In a few seconds it tottered and fell, and in a few more became motionless; it did not recover on exposure to the air.

Chlorine.-On the 22nd January exposed a fly of the same kind as the last to this gas, as disengaged in the tube by the action of dilute sulphuric acid on a mixture of common salt and black oxide of manganese. In less than two minutes the fly became motionless. Taken out immediately and exposed to the air, it did not revive.

\section{On the Action of Vapours.}

Ammonia.-On the 3rd January put a fly (Heteromyza buccata) into a tube, with a few drops of strong aqua ammonice. At first it was active and restless; in about half a minute it fell down, moving its legs; in another half-minute it was motionless. It had not come in contact with the fluid. Taken out it did not revive.

Exposed another fly (Musca lanio) in the same manner to the ammoniacal vapour; it presently exhibited convulsive movements; in less than a minute it was motionless, and it remained so, for several hours, after exposure to the air ; the following morning, it was found revived and active.

Muriatic Acid.-Exposed a fly of the same kind to the vapour of strong muriatic acid: during the first half-hour the fly was active, it gradually became less so ; after about two hours it was found motionless. Taken out of the tube, after showing no signs 
of life for an hour or two, it revived, and recovered its activity. Replaced, and kept exposed to the acid vapour for twenty-four hours, it was found dead when taken out.

A fly (Piophila casei) was put under a small wine glass, on a glass support, and with it a portion of cotton wool moistened with the acid. In less than a minute the gait of the fly became tottering ; and in less than five minutes it was motionless. It was immediately taken out, but it did not revive. A similar experiment was made on another fly (Heteromyza?), somewhat larger and more vigorous. After about a quarter of an hour it became motionless. Then taken out, in a few minutes it became pretty active.

Nitric Acid.-The results of two trials with the vapour of this acid, one on a Piophila, the other a Heteromyza, differed chiefly from those last mentioned in being, in each instance, fatal, exhibiting, after deprivation of motion, no sign of revival, though taken out immediately.

Alcohol. - Put a fly (Musca lanio) into a tube with a little alcohol of Sp. Gr. 84 underneath, and raised its temperature to $74^{\circ}$. For a few minutes the fly showed increased activity; in a few more it became nearly motionless; after about a quarter of an hour it appeared to be torpid. Now, exposed to the air of the room, in a few minutes a slight motion of its feet was seen; after a couple of hours it was nearly as active as before the experiment ; two hours later it was found dead.

On the Sth of January, temperature of the room about $58^{\circ}$, placed two small flies (Sciara vitripennis, Psychoda nervosa) under a wine glass, on a glass support, with a portion of cotton-wool moistened with alcohol. The first effect was an increase of activity; after a few minutes their irregular movements and occasional falls suggested an inebriated state. A drop of alcohol poured on them rendered them motionless instantly, and proved fatal to them.

On the 11th January a similar trial was made on another fly (Heteromyza buccata), at a raised temperature of $70^{\circ}$. The excitement first produced, marked by increased activity, was soon followed by feebleness, irregular movements, and death. Similar effects were produced by the vapour of alcohol on another fly of the same kind, at the temperature of the room $57^{\circ}$, but not quite so rapidly.

Ether.-On the 12th January placed a fly (Musca lanio) in a tube with a little sulphuric ether, at the temperature of the room 
$56^{\circ}$. It immediately became motionless. Taken out after a few minutes it soon revived, and seemed as active as before. Replaced in the tube after an interval of two hours, it did not become torpid so soon as at first, two or three minutes elapsing; it revived in about a quarter of an hour after being taken out.

Repeated the experiment on another fly (Heteromyza buccata) at a temperature of about $54^{\circ}$. In a few seconds the fly dropped from the side of the glass motionless; so it continued till taken out. Taken out, after ten minutes, it did not revive. Repeated, on another fly of the same kind, the immediate effect was the same. Taken out, in less than a minute, in about an hour it revived and was active as before.

Chloroform.-On the 14th January, at the temperature of the air of the room, placed a fly of the same kind as the last under a wine glass, with a portion of cotton-wool moistened with chloroform. For a second or two the insect was active; then it suddenly became motionless. Taken out, it was tolerably revived in an hour. Repeated the experiment on a small gnat, with a like effect in every respect. Repeated it on the fly and the gnat, keeping them in the vapour about eight minutes; they soon became motionless as at first, but they did not revive on exposure to the air.

Camphor.-A fly (Heteromyza buccata) put under a wine glass at the temperature of the room, with a piece of camphor, became torpid in about half an hour; after exposure to the air for about the same time it revived, moving sluggishly. Replaced, and left over night under the glass, with the camphor, on the following morning it was found dead. Repeated the experiment with another fly of the same kind. In rather less than half an hour its activity was diminished; some five hours later it was motionless; it did not revive on exposure to the air.

Oil of Turpentine.-On the 20th January placed two flies, of the same kind as the last, under a wine glass, with a portion of cotton wool moistened with this volatile oil. In a minute or two they walked unsteadily, as if intoxicated; in less than a quarter of an hour they were found motionless, they had become smeared with the oil ; they did not revive on exposure to the air. Another fly, of the same kind, placed in a tube with a portion of oil, separated by a diaphragm, pervious to the vapour, at a temperature of about $75^{\circ}$, soon became motionless, and did not recover when taken out. Repeated the experiment on another fly of the same 
kind at the temperature of $54^{\circ}$; the immediate effect was the same, in a few seconds it had lost the power of walking on the perpendicular side of the glass tube, and was more restless than before; accidentally a small portion of its surface came in contact with the oil, in less than half a minute it became motionless: immediately taken out it did not revive. The experiment repeated on another fly of the same kind, not allowed to come in contact with the oil ; it became motionless in a minute, aiter having been instantly affected in the same manner as the preceding; taken out, after about two minutes, it did not revive. Repeated the experiment on a small fly.

Strong Acetic Acid.-A fly (Heteromyza buccata), exposed to the vapour of this acid at about $56^{\circ}$, was not immediately apparently affected, nor after five hours ; after ten hours it was found motionless; it did not revive when taken out. The trial was repeated on another fly of the same kind, with a like result, and also on a gnat; in about five minutes it became motionless; taken out, after about two hours, it was found to be dead. Repeated it on another fly (Heteromyza buccata), in about half an hour it ceased to move; allowed to remain in about two hours, it did not revive when taken out.

Attar of Roses.-Placed a fly (Heteromyza buccata) under a wine glass, with a portion of paper on which a drop of this essential oil had been let fall; temperature of the room $54^{\circ}$. At first the fly did not appear to be affected; in about an hour it had become dull, moving languidly ; five hours after it was found motionless. Taken out it showed marks of revival in about half an hour; after three hours it had recovered its activity. Repeated the experiment on a small fly-a gnat; after an exposure of about two hours it was found motionless; taken out it did not revive.

Musk.-Placed a fly (Heteromyza buccata) under a wine glass with a portion of this substance, adding a few drops of water to favour the rise of the odorous effluvia. After twelve hours no appreciable effect was produced; the activity of the insect was not impaired. Repeated the experiment on a gnat and another fly, the species of which was not determined, and with a similar result; one was exposed to the odour for twelve hours, the other, the latter, for twenty-four: this insect, on lifting up the glass, took wing and escaped.

Iodine.-Exposed a fly (Musca domestica) to the vapour of this substance at $70^{\circ}$; the air in the tube was only just perceptibly 
coloured. During the first half hour the fly was active, and seemed little affected; after another half hour it was found motionless; whether it revived or not is not mentioned in the note of the experiment. The experiment was repeated at the temperature of the air of the room, $55^{\circ}$, on two flies (Heteromyza buccata); one, which was feeble when put into the tube, became motionless in about a quarter of an hour; the other, in the same time, excepting that it had become dull, seemed but little affected; in about an hour its gait was unsteady, as if its muscles were no longer under control; after four hours it was found motionless; neither of them revived.

On the results described in the two last sections I beg to offer in conclusion a few remarks.

Comparing the effects of the several agents no two seem to have acted precisely in the same manner; and probably were a larger number of experiments made, and with minute attention, each agent would be found to possess some peculiarity in its influences. Those most fatal to life appear to have been sulphuretted hydrogen, ammonia, chlorine, nitric acid, iodine, camphor, oil of turpentine, each varying in degrees of rapidity of effect, but so far analogous that no perfect revival ensued on exposure to the air, after a motionless state had once been induced. Those less fatal to life appear to have been azote, hydrogen, carbonic acid, coal gas, muriatic acid vapour, ether, chloroform,-all of them producing immobility, and probably insensibility, with different degrees of rapidity, but not commonly terminating in death, revival in most instances following. Whether oxygen belongs to either is more than doubtful; it seems to stand alone, as regards its effects on the functions of life, throughout all classes of animals. That death sooner occurred in the trial with it than in that with atmospheric air, may have been owing to exhaustion connected with increased vital action of the insect, unsupported by nourishing food.

How the effects of the several agents are produced, it may be difficult to explain in the present state of our knowledge. Some of them probably act chemically, such as the strong acid vapour, chlorine, iodine: some probably, chiefly, in suspending respiration, or in preventing the due aëration of the fluids, such as azote, hydrogen, carbonic acid; and others, it may be, in a more complicated manner, and in part through their action on the nervous as well as the respiratory system, such as sulphuretted hydrogen, ether, chloroform, alcohol, oil of turpentine, camphor.

It is worthy of remark, that most of the substances, which, even 
in minute portions mixed with common air, prevent the slow combustion of phosphorus, as indicated by its shining in the dark, have the effect, on the insects on which they were tried, of suspending animation.

The revival which occurred in so many instances after suspended animation, may probably be connected with that tenacity of life and long enduring excitability for which insects are remarkable: thus, even when decapitated, the common house fly, or the flesh fly, will not unfrequently move its himbs twenty-four hours after the loss of the head on being touched, and commonly can be excited to action beyond twelve hours after such a mutilation.

Some of the results may not be undeserving notice for practical purposes, - as those in the instances of sulphuretted hydrogen, oil of turpentine, and camphor, in relation to the destruction of parasitical insects, whether infesting plants or minerals, or to the preservation of substances from the attacks of insects. To be applicable to the preservation of plants, of course it is necessary that the agents to be used should not exercise on them any material injurious effects. This must be determined by experiments made expressly for the purpose. The few trials I have yet made on seeds seem to show, that the steeping them in a solution in water of sulphuretted hydrogen has not prevented their germination. The seeds tried were mignionette, cress seed, and that of a Nemophila : analogy, viz. that of steeping the seed of the Cerealia in a solution of the white oxide of arsenic, is in favour of the same conclusion. Further, for the preservation of articles, whether of clothing or furniture, it is hardly less necessary that the substances to be employed should have no offensive odour. Judging from the effects of attar of roses, and from what we know of scented woods not being liable to be attacked by insects, the probability is that any volatile oil of agreeable perfume will answer the purpose required, and prove a true instance of the utile et dulce combined.

As carbonic acid gas, and some of the other agents mentioned, produce merely a temporary torpor, it may be a question whether this gas, or simple immersion in water, may not be advantageously substituted for the fumes of burning sulphur, destructive of life, at the yearly gathering of honey; the former, indeed, may be said to be in use in the Levant, where the smoke of the fire of leaves, in which the carbonic acid generated may be considered as chiefly operative, is employed to stupify the bees preparatory to the spoiling of their hives. 
The tenacity of life in insects, as exemplified in their suspended animation, whether from want of free air,-as when immersed in water, or buried in the earth, or surrounded by azote or carbonic acid, may serve a useful purpose in the economy of nature. They are the favourite food of many birds and fishes; and in their torpid state, with just sufficient life to preserve them from decomposition, they are most easily obtained, and that at a time when such a supply is peculiarly wanted; and even their quitting their state of torpor in temperate weather in winter, when they themselves appear to exist without food, may conduce to the same end, - the affording of food to other animals higher in the scale of organization, and especially such as are roused from a like state of torpor by elevation of temperature.

Lesketh How, Ambleside, I am, my dear Sir, Yours very truly,

March 19th, 1851.

\section{J. Davy.}

To William Spence, Esq.

F.R.S., \&c.

P. S.-In the note with which you have favoured me of the 15 th of April, you have called my attention to the effects of the vapour arising from the bruised leaves of the common laurel on insects, and also to that of prussic acid. Before describing the experiments I have made in consequence, I shall, with your permission, quote your words :- "There is," you remark, "one vapour, on which, though now employed to kill insects, we want more exact facts-that of the prussic acid let loose from the bruised leaves of the common laurel. Entomologists find that insects introduced into a wide mouthed phial, having a few of these bruised leaves at the bottom, die almost instantly; but there is this inconvenience in employing them, that the watery vapour, which they also give out, condenses on the side of the phial, and injures the wings of the flies, \&c., put into it." You add: "It would be desirable to know how small a quantity of the vapour of prussic acid suffices to kill an insect of medium size; whether some insects (as beetles) are less affected than others (as flies, \&c.), and whether the size of the insect has any thing to do with the result."

Preparatory to making any trials with the prussic or hydrocyanic acid, I thought it right to institute one or two with the bruised leaves of the laurel.

Two leaves just gathered, torn into small pieces, and bruised in VOL. I. N. S. PART VII.-DEC. 1851. 
a mortar, were put under an inverted glass in which were confined a honey bee and two small insects of the knat kind. In about five minutes they had all been rendered motionless; one of the small flies did not revive; the other and the bee recovered in a few hours, symptoms of revival appearing even before they were taken from beneath the glass into the open air. Probably had the experiment been made at another season, in summer or autumn, the effect would have been different; be this as it may, the result was not of a kind to induce me to make at the time any further trials of the leaves, especially after instituting some with the hydrocyanic acid, the fatal agency of which exceeded my expectations.

With a view to answer your inquiries respecting this acid, I paid attention to quantities. Two glass tubes, each closed at one end, a small and a larger one, were selected for the experiments; the larger of three cubic inches and a half capacity, and seventenths of an inch wide, the smaller only one-tenth of an inch in width, and little more than an inch long. The small tube, charged with three-tenths of a grain of prussic acid, was introduced into the larger, in which had just before been placed three flies.

The tube was finally closed with a cork. In less than two minutes one of the smaller flies, and also the larger, dropt down, and, after a few convulsive movements, became motionless, as did the other in about half a minute more (it was further removed from the acid), but without convulsive action. Taken out in less than half a minute, and exposed to the air of the room at $55^{\circ}$ Fahrenheit, they did not revive. The small tube, immediately weighed, had not sustained any appreciable loss.

Repeated the experiment, using the same portion of acid on another fly (a Heteromyza). It became motionless in as short a time, but it revived when exposed to the open air. Placed again in confinement, with only $\cdot 04$ grains of prussic acid in the small tube, in five minutes it became motionless. Immediately taken out, it was found revived after an hour, and so active that it escaped by taking flight.

Placed a honey bee just caught in the garden at noon, under a wine glass inverted, of about four cubic inches capacity, with the small tube charged with $\cdot 16$ grains of prussic acid. In about two minutes the bee fell down and was convulsed in its legs and abdomen; all motion ceased in about eight minutes. Taken out immediately, symptoms of revival appeared in about three hours; soon after it was standing on its legs, but not active: the following morning it was found dead. 
Placed the small tube containing the prussic acid instantly after the experiment on the bee under another wine glass, in which was confined a Bombus (B. hortorum), just caught, and very active. During the first minute or two its wings were in constant motion; during the next four or five it moved about in an irregular manner, its legs alone acting; in about ten minutes motion ceased, except a slight tremulous one of the legs; - now several parasitical insects (Acarus - ? ) dropt from it, deprived of motion themselves; in about twenty minutes it was altogether motionless. The tube taken out and weighed was found to have sustained no appreciable loss; it was replaced under the wine glass. In about three hours, though still confined under the wine glass, the humble bee began to revive, and the following morning it was pretty active; none of the parasitical insects revived excepting one.

Placed another Bombus under a wine glass, with the small tube charged with $\cdot 08$ grains of prussic acid. In less than a minute it was motionless, as were also two or three of the parasitic insects (the same kind as the preceding), which fell from it when the poison began to take effect. In less than two hours it had tolerably revived. Now added a single drop of the acid, in about ten minutes the humble bee, after being slightly convulsed, became motionless. On the following morning it was found alive, moving its feet feebly.

Substituted for the small tube one a little larger, its mouth two-tenths of an inch in diameter, its capacity one-tenth of a cubic inch. After pouring into it 7 grains of prussic acid, it was suspended by a thread in the larger tube, and so used in the following trials.

Introduced a large vigorous beetle (Geotrupes stercorarius), and closed the receiving tube with a cork so as to prevent the escape of the vapour of the dilute acid. In about a minute the beetle became motionless. Taken out after two hours and a quarter it was found dead.

Next introduced an active Bombus. In a few seconds it became motionless-entirely motionless. Taken out after an hour it exhibited no signs of revival; it was dead.

Introduced another active Bombus. It too in a few seconds was rendered motionless. Taken out after about a minute, it showed no signs of revival for many hours; but the following morning it was found tolerably revived. Replaced in the tube with the acid, and left there three hours, it did not recover when taken out. The tube, now weighed, was not found to have sus- 
tained any appreciable loss, - a circumstance which perhaps might have been anticipated, considering that the prussic acid used was the dilute hydrocyanic acid of the London Pharmacopœia, which contains 2 per cent. only of real acid.

These few experiments may perhaps suffice to show the great efficacy of the acid, the intensity of its action, and the very minute quantity requisite to occasion death, and that in a few seconds (at least a motionless state terminating in death, exposure to the acid vapour being prolonged), of such powerful and comparatively large insects as the Bombus hortorum and Geotrupes stercorarius; and, further, in conjunction with the qualities of the acid, especially its great volatility, the boiling point of the pure acid being only $79^{\circ}$ Fahrenheit, the manner in which it should be used when employed for the purposes of the Entomologist.

As to precautions, the poison being so volatile, it need hardly be remarked, that a close tube (one made air tight, by a good cork, will be best) ought to be used for confining the insects to be acted on; and, on the same account, that the receiving tube should not be very capacious, nor the small tube or bottle to be included in it, charged with the acid, one of narrow or contracted aperture. The dimensions of the two duly proportioned, the effects, deprivation of life, even from a few grains of the acid, should be almost instantaneous and quite certain, and this at the ordinary temperatures of our rooms, supposing them to range throughout the year between $50^{\circ}$ and $70^{\circ}$. As to bad effect from moisture, there appears to be no ground for apprehension, insomuch as in the short time the effect is being produced, even should the insect be allowed to remain in the tube more than an hour, there will be no appreciable loss from the ascent of aqueous vapour; and, even if there were, it would be most easy to counteract its influence by the introduction in another small tube of a few drops of strong sulphuric acid, or grains of chloride of calcium. As, in the instance of the Bombus, the prussic acid proved destructive to the parasitic insects infesting it, it is not improbable that it may be equally fatal to parasitic animals generally, and their ova and larvæ. If so, would not this be an additional inducement to employ it, and no small advantage?

April 19, 1851.

J. D. 


\section{$2 \mathrm{BHL}$ Biodiversity Heritage Library}

Davy, John. 1851. "XXV. On the Effects of certain Agents on Insects, in a Letter addressed to William Spence, Esq., F.R.S., \&c." Transactions of the Entomological Society of London 6, 195-212.

https://doi.org/10.1111/j.1365-2311.1851.tb02500.x.

View This Item Online: $\underline{\text { https://www.biodiversitylibrary.org/item/55127 }}$

DOI: https://doi.org/10.1111/j.1365-2311.1851.tb02500.x

Permalink: https://www.biodiversitylibrary.org/partpdf/56859

\section{Holding Institution}

Smithsonian Libraries

\section{Sponsored by}

Smithsonian

\section{Copyright \& Reuse}

Copyright Status: Public domain. The BHL considers that this work is no longer under copyright protection.

This document was created from content at the Biodiversity Heritage Library, the world's largest open access digital library for biodiversity literature and archives. Visit BHL at https://www.biodiversitylibrary.org. 